\title{
Impediments to Learning Object Reuse and Openness as a Potential Solution
}

David Wiley

david.wiley@gmail.com

Follow this and additional works at: https://scholarsarchive.byu.edu/facpub

Part of the Educational Psychology Commons

\section{Original Publication Citation}

Wiley, D. (29). Impediments to Learning Object Reuse and Openness as a Potential Solution. Revista Brasileira de Informática na Educação, 17(3).

\section{BYU ScholarsArchive Citation}

Wiley, David, "Impediments to Learning Object Reuse and Openness as a Potential Solution" (2009). Faculty Publications. 1232.

https://scholarsarchive.byu.edu/facpub/1232 


\section{Impediments to Learning Object Reuse and Openness as a Potential Solution}

\author{
David Wiley \\ Brigham Young University \\ email:david.wiley@byu.edu
}

\section{Reuse and Metaphor}

The idea of smaller, modular, reusable instructional components is not new - in the late 1960s researchers were declaring that "curricular units can be made smaller and combined, like standardized Meccano [mechanical building set] parts, into a great variety of particular programs custom-made for each learner" (Gerard, 1969; as quoted in Gibbons, 2002). Nelson extended and generalized the concept of granular media that can be mixed and matched to all content with his Xanadu and OSMIC system designs in the 1980s, calling the primordial bits of content "primedia." After the popularization of the Internet and World-Wide Web, Hodgins coined the term we now know, "learning object," with an explicit reference to Legos (echoing Gerard's comparison to children's toys) and an implicit reference to object-oriented programming.

Unspoken in each of these metaphors - Meccano parts, Legos, "primedia" - is an assumption that the primary mode of reusing these components is assembly. Generally speaking, children don't break Legos in half, melt them down, or paint them new colors. They use a Lego exactly as they receive it, in combination with a number of other Legos, to produce an almost infinite number of creative aggregations and structures.

The intellectually confining power of our everyday experience with Legos is difficult to appreciate. These experiences tend to preclude our understanding the term "reuse" in its broader sense - adaptation of the thing itself to better suit our circumstances. The historically prevailing learning objects metaphors have limited our vision of reuse to "inclusion of a learning object in a novel aggregation" and prevented us from seeing reuse as "the possibility of changing the learning object itself in substantive ways."

\section{Reuse and Copyright}

Metaphor is not the sole bar of the cage restraining our thinking about the reuse of learning objects. According to the terms of the Berne Convention (to which the
US became party in 1989), every creative work (including educational materials like learning objects in addition to literary, cinematic, and other cultural works) is fully and internationally copyrighted automatically at the moment of its creation, without registration or other administrative requirement. We have lived in this world for almost 20 years now.

The restrictions of copyright law and its accompanying penalties are ambient factors in our everyday lives. "Everyone knows" you're not allowed to make a copy of a textbook, article, or simulation without permission ${ }^{1}$. The technically daunting and time-consuming process of requesting permission, and the inevitable fees associated with that permission if granted, prevent law-abiding individuals and organizations from reusing most of the learning objects they find on the Internet or in repositories.

"Everyone knows" that you're also not allowed to make changes to a textbook, journal article, or simulation. Our assumptions about copyright law prevent us from thinking that the construct "reuse" might include making changes to the learning object itself. This kind of changing-the-thing-itself is known legally as creating a "derivative work," and is defined under Section 101 of the 1976 U.S. Copyright Act is:

a work based upon one or more preexisting works, such as a translation, musical arrangement, dramatization, fictionalization, motion picture version, sound recording, art reproduction, abridgment, condensation, or any other form in which a work may be recast, transformed, or adapted.

Like the invisible mental constraints of the learning objects metaphors, the ubiquitous constraints of copyright also prohibit our thinking about reuse in broader

\footnotetext{
${ }^{1}$ Fair Use (and the related idea of Fair Dealings in the Commonwealth countries) is difficult enough to understand in the clearest cases - ones wherein a person wants to make unauthorized copies of textbook chapters or research articles. These issues become significantly more complex when a person desires to make unauthorized derivative works.
} 
ways, because the right to create derivative works is one of the rights reserved for the rights holder under copyright law. Consequently, the thought-shaping power of the popular learning objects metaphors and the influence of ambient copyright have needlessly restricted our thinking about the reuse of learning objects.

\section{A Broader Definition of Reuse}

In setting out a basic definition of usage rights to open content, Wiley (2007) describes four ways open content can be used for free and without requesting permission:

1. Reuse - Make and use verbatim copies of the work, just as you found it

2. Revise - Alter or transform the work so that it better meets your needs

3. Remix - Combine the (verbatim or altered) work with other works to better meet your needs

4. Redistribute - Share the verbatim work, the revised work, or the remixed work with others

In this broader framework, now known as "the 4Rs," the kind of reuse traditionally considered for learning objects - making and using verbatim copies and aggregating these unaltered learning objects into bigger instructional units - is only half the universe of use imagined. How can we activate the additional use rights for learning objects, increasing their power and usefulness in the process?.

\section{Openness and Reuse}

A number of people and organizations have developed copyright licenses that an author or other copyright holder can apply to any creative work, including learning objects. These licenses grant 4Rs usage rights to others for free (without cost) and without the need to seek additional permission before engaging in any of the 4Rs uses.

These licenses include the Creative Commons licenses (http://creativecommons.org/), the GNU Free Documentation

License (http://www.gnu.org/copyleft/fdl.html) and the Open Publication License (http://opencontent.org/openpub/). The most widely adopted of these licenses are those provided by Creative Commons, which are currently applied to hundreds of millions of media assets across the Internet.

One of the most influential supporters of openness generally and Creative Commons licenses specifically is Brazilian Minister of Culture, Gilberto Gil. In a 2007 interview with the New York Times' Larry Rohter, Gil said, "My personal view is that digital culture brings with it a new idea of intellectual property, and that this new culture of sharing can and should inform government policies" (Rohter, 2007). Rohter goes on to state that "one of Mr. Gil's first actions after becoming culture minister in 2003 was to form an alliance between Brazil and the nascent Creative Commons movement.”

\section{Openness as a Potential Solution for Learning Object Reuse}

Popular learning objects metaphors and our copyright-shaped habits of thinking control the ways we think about the reuse of learning objects. However, new metaphors can be created and new copyright licenses can be applied. For the last decade thousands of researchers have developed processes and strategies for designing, storing, managing, and providing access to learning objects, including metadata standards, repository specifications, and interchange formats. However, few have paid attention to the legal status of learning objects themselves and the unintended consequences of fully copyrighted learning objects on teaching and learning.

Existing standards and approaches do not need to be revised in order for open licenses to be applied to learning objects. For example, the IEEE Learning Object Metadata (LOM) standard already includes an entire metadata category dedicated to the expression of the Rights associated with a learning object, and Creative Commons licenses can be expressed straightforwardly within this category. In fact, nothing about the ways we design, store, manage, or provide access to learning objects needs to change in order for an open license to be applied. All that is required is a new, broadened understanding of the notion of "reuse" and a desire to see learning objects succeed in reaching their full potential as an educational technology.

\section{Conclusion}

This paper has argued that the simple act of adding an open license providing 4Rs usage rights to learning object users will significantly expand our understanding of "reuse;" that the application of open licenses will greatly increase the reach of learning objects (making them available to individuals and organizations with financial or other resource challenges), and that open licenses are easy to apply to learning objects. Because of the challenges inherent with fully copyrighted learning objects, "open learning objects" seem to be the best path forward for this very promising educational technology.

\section{References}


[1] L. Rhoter. Gilberto Gil Hears the Future, Some Rights Reserved, 2007. Available at: http://www.nytimes.com/2007/03/11/arts/music/ 11roht.html?_r=2\&oref=slogin\&pagewanted=pr int. Access in: 19/02/09.

[2] D. Wiley. Open education license draft, 2007. Available at: http://opencontent.org/blog/archives/355. Access in: $19 / 02 /$ 